International Research Journal of Materials Sciences and Applications

(ISSN:2575-1034)

\title{
Evaluation of commercial and fresh-picked Origanum vulgare after dehydration
}

\begin{abstract}
Vanessa Cristina dos Santos Peixoto de Oliveira1, Maria Inês Bruno Tavares1, Eduardo Miguez Bastos da Silva1, Paulo Sérgio Rangel Cruz da Silva1, Tiago Venâncio2
\end{abstract}

1Universidade Federal do Rio de Janeiro, Instituto de Macromoléculas Professora Eloisa Mano, Av Horácio Macedo 2030, Bloco J, Centro de Tecnologia, Ilha do Fundão, Rio de Janeiro, RJ, Brazil, CEP 21941-598 2Departamento de Química, Universidade Federal de São Carlos, São Carlos, SP, Brazil

\section{ABSTRACT}

Origanum vulgare Lamiaceae is one of the most used condiments in many countries, and is used in the perfume industry and also in folk medicine. To evaluate the composition of this plant due to its heterogeneity, the main objective was analyze origanum in commercial form and fresh picked after treated at different temperatures, using mainly solid-state NMR techniques, as well as FTIR, XRD and TGA were applied, showing possible existence of larger molecules and structures with low molar mass due to difference of mobility presented by molecules. We observed the carbon-13 signals' intensity and the signals detection or not varied according to kind of oregano studied as well as the thermal treatment temperature. The techniques are efficient in determining the compounds present in such heterogeneous material, although they are difficult to apply. The HR-MAS confirmed the existence of major compounds such as water, fixed oils, terpenes and polysaccharides.

Keywords: Origanum vulgare L; polysaccharides; NMR; heterogeneity.

*Correspondence to Author:

Maria Inês Bruno Tavares. Universidade Federal do Rio de Janeiro, Instituto de Macromoléculas Professora Eloisa Mano, Av Horácio Macedo 2030, Bloco J, Centro de Tecnologia, Illha do Fundão, Rio de Janeiro, RJ, Brazil, CEP 21941-598 How to cite this article:

Oliveira et al.,. Evaluation of commercial and fresh-picked Origanum vulgare after dehydration. International Research Journal of Materials Sciences and Applications, 2017; $1: 2$.

\section{eSciencePublisher}

eSciPub LLC, Houston, TX USA. Website: http://escipub.com/ 


\section{1-INTRODUCTION}

Medicinal plants have been used by humans to cure illnesses and wounds and alleviate symptoms since before the dawn of civilization. However, since the mid-twentieth century, the use of synthetic drugs has been more common than the use of medicinal plants, especially in developed Western society, while in developing countries medicinal plants are still widely employed. This use is certainly due to the high price of most synthetic drugs.

In Brazil, herbal medicines are still commonly used in primary health care in many areas. Indeed, their use is expanding in some cases, due variously to the adverse effects of synthetic drugs, consumer preference for "natural" treatments (Sivropoulou, 1996) and growing scientific validation of the pharmacological properties of plant species, confirmed by the development of new analytical methods to help develop new products and administration forms with relatively low cost (Chen et al. 2005; Gligorov and Lotz, 2004). However, many preparations employing medicinal plants still require further scientific studies, including chemical standardization, biological testing in vitro and in animal models and clinical evaluation.

The fact that many medicinal plants are used to treat various diseases is mainly due to the vast number of chemical compound classes, making plants very heterogeneous (Baratta et al. 1998, Souza et al., 2005, and Hijo et al, 2014). Oregano (Origanum vulgare) is a plant that has this feature. It is used in several areas such as cooking, medicine and cosmetology. Among the classes of compounds present in oregano are phenolic compounds such as rosmarinic acid, caffeic acid, protocatechuic acid, resveratrol, catechin, catechol, coumaric acid and quercetin. These phenolic compounds contain other compounds, such as alcohols, esters, aldehydes, terpenes, phenols, organic acids and other components, where those described in the literature (Teixeira et al., 2013; Souza et al., 2005). Other important constituents in the formation of plants are polymers, including polysaccharides, and cellulose fibers (Tavares et al., 2003). Cellulose, hemicellulose and lignin, for example, are very common polysaccharides in plants, constituting 40 to $50 \%$ by weight.
Studies have shown that spectrometric techniques can identify the major classes of compounds or components present in the majority medicinal plants, confirming the results found by IR spectroscopy, a powerful technique to identify the structure of materials. Nuclear Magnetic resonance have been very much used to analyze food materials, many studies involves this technique because this spectroscopy allows to obtain different type of information on those material, due to those characteristics as amorphous and heterogeneous (Sacchi et al, 1997; Claridge, 1999; Hills et al., 1999; Cornillon and Salim, 2000; Harris, 2000; Mannina et al, 2003; Knothe, and Kenar, 2004; Salomonsen et al., 2007; Preto et al., 2011; Preto et al., 2013). One of the high-field NMR techniques that have been used with a successful is HR-MAS, which provides ${ }^{1} \mathrm{H}$ spectra of solid materials very similar to the liquids, with very good resolution, allowing obtaining information's on natural samples without pre-treatment and in its (Fauhl et al., 2003, Preto et al., 2013). It is very promising in the study of heterogeneous solids. Through the high-resolution magic angle spinning technique, HR-MAS has been applied to study intact plant materials such as leaves, flowers and fruits, and animal liver, brain, lung, kidney, among others (Sacoo et al., 1998, Costa et al., 2007, Preto et al., 2013).

The HR-MAS is based on the fact that both plant and animal materials in their natural state have water molecules in their cells, in the amount required to provide mobility of metabolites (primary and secondary). This fact allows obtaining spectra with excellent resolution, requiring only the addition of one or two drops of deuterated solvent, properly chosen not to cause dissolution of the constituents of the sample. Typically $\mathrm{D}_{2} \mathrm{O}$ is used to adjust the homogeneity of the magnetic field. An example of the potential of this technique was reported by Lião and coworkers (2010) and Costa and collaborators (2007), described the application of ${ }^{1} \mathrm{H}$ NMR spectroscopy, in particular using HRMAS for the analysis of common bean cultivars. The technique allowed the separation of different bean varieties into four different groups according to the chemical composition. It also allowed the identification of cultivars having the highest relative content of raffinose, stachyose, oligosaccharides and verbascose. All analyses 
were conducted without the need to use any pretreatment or extraction of the samples.

Another study analyzed different commercial samples of Maytenus species using techniques such as thermogravimetric analysis (TGA), infrared analysis (FTIR), and nuclear magnetic resonance (NMR), to investigate the authenticity of such species (Preto et al., 2013). According to the authors, TGA enabled the identification of water and volatile components from 200 to 300 ${ }^{\circ} \mathrm{C}$ and polysaccharides such as cellulose and hemicellulose in the range of 350 to $700{ }^{\circ} \mathrm{C}$ in most samples. The FTIR technique was essential to confirm the presence of some compounds already observed by TGA. The NMR technique was useful in detecting proteins, polysaccharides, fibers and adsorbed water. These compounds were identified according to the relaxation times and three specific domains related to moisture, fixed oil and the third one associated to fibers and polysaccharides, corroborating the results of the previous tests.

The present work focus on an evaluation of the composition of commercial and fresh-picked oregano and after being subjected to dehydration/ degradation at different temperatures $\left(25^{\circ} \mathrm{C}, 37\right.$ ${ }^{\circ} \mathrm{C}, 50^{\circ} \mathrm{C}, 100{ }^{\circ} \mathrm{C}, 150{ }^{\circ} \mathrm{C}, 180^{\circ} \mathrm{C}$ and $195^{\circ} \mathrm{C}$ ). For this it was employed TGA, EDX, FTIR and HR-MAS, which allowed identifying possible structural rearrangements due to the dehydration process.

\section{2-EXPERIMENTAL PART}

\section{1-Dehydration Treatment}

Samples of fresh-picked and commercial oregano were acquired and submitted to dehydration by heating in a forced-air oven for 60 minutes at different temperatures $\left(25^{\circ} \mathrm{C}, 37\right.$ ${ }^{\circ} \mathrm{C}, 50^{\circ} \mathrm{C}, 100{ }^{\circ} \mathrm{C}, 150^{\circ} \mathrm{C}, 180^{\circ} \mathrm{C}$ and $195^{\circ} \mathrm{C}$ ). After preparation, the samples were analyzed by techniques for characterization.

\section{2-Thermogravimetric analysis (TGA)}

The thermal stability of the materials after been dehydrated at different temperatures was investigated by thermogravimetric analysis, using a TA Instruments Q500 analyzer with precision of $\pm 1^{\circ} \mathrm{C}$. The TG measurements were obtained by heating the samples from $30^{\circ} \mathrm{C}$ to $600^{\circ} \mathrm{C}$ at a rate of $10^{\circ} \mathrm{C} / \mathrm{min}$ in nitrogen atmosphere.

\section{3-Energy-dispersive X-ray spectroscopy (EDX)}

This technique was carried out in view of the TGA results, which showed a percentage of possibly inorganic residues. The samples were then analyzed in a Shimadzu EDX 720 spectroscope.

\section{4-Fourier-transform infrared spectroscopy (FTIR) analysis}

The FTIR analyses were performed using attenuated total reflection mode with a Varian Excalibur $3100 \mathrm{FTIR}$ spectrometer, in a scanning range of $4000-600 \mathrm{~cm}^{-1}$, collection time of 25 seconds, with 128 scans and normal resolution spectrum. The analyses was carried out at $25^{\circ} \mathrm{C}$ and reference material (calibration) used in the ATR analysis was a zinc selenite crystal.

\section{5 -High resolution magic angle spinning (HR-MAS)}

The ${ }^{1} \mathrm{H}$ HR-MAS spectra were obtained in the NMR laboratory of DQ-UFSCar with a Bruker Avance DRX 400 9.4 T spectrometer (400.21 $\mathrm{MHz}$ for ${ }^{1} \mathrm{H}$ ). The plant material was powdered and two drops of deuterated water was added to adjust the magnetic field homogeneity.

\section{3 - RESULTS AND DISCUSSION}

The degradation curves of dehydrated freshpicked and commercial oregano showed a similar profile, detecting at least two stages of degradation, after being subjected to thermal analysis (Figure 1). The results showed an initial mass loss of the system at around $60^{\circ} \mathrm{C}$, which can be attributed to loss of water, essential oils and other compounds with low molecular weight present in oregano (Hijo et al., 2014).

The loss of these compounds was more noticeable in the fresh-picked oregano, especially in samples dehydrated at $60{ }^{\circ} \mathrm{C}$. This behavior was expected since fresh-picked oregano contains a high concentration of water, essential oils, fatty acids, etc., while commercial oregano undergoes a preliminary dewatering process to increase its shelf life. Note in both curves that the degradation values are in the range of 240 to $400{ }^{\circ} \mathrm{C}$, in line with other reports in the literature. The presence of components with low molecular weight may favor increased rigidity, since they can act as plasticizers of cellulose and lignin 
chains and the system as a whole, generating different interactions. Thus, rigid structures require higher vibrational energy, in turn requiring higher temperature for the degradation process.

EDX analyses were also performed on the commercial and fresh samples. This technique was performed after the results of TGA, which demonstrated that after degradation of the material, a variable amount of inorganic residue remained (between $25 \%$ and $35 \%$ ), which can be mainly attributed to minerals.

EDX analysis showed that all the oregano samples contained inorganic compounds, such as $\mathrm{K}, \mathrm{Ca}, \mathrm{Mg}, \mathrm{Si}, \mathrm{Cl}, \mathrm{S}, \mathrm{Al}, \mathrm{Fe}, \mathrm{P}, \mathrm{Mn}, \mathrm{Zn}$, Mo and $\mathrm{Ti}$, among others, with different percentages depending on the prior heat treatment.

The existence of these compounds in oregano samples is in agreement with the data available in the literature on the existing mineral structures in the leaves of plants in general. Minerals like potassium, calcium, magnesium, sulfur, boron, copper, iron, manganese and zinc can be essential components for plant growth (Malavolta, 2006). The percentage of each of the compounds varied in the samples, due to the complexity and heterogeneity of their nature. However, the compounds with the highest concentration in all samples were in general $\mathrm{K}$ and $\mathrm{Ca}$, while the others were present in lower amounts. This is because compounds such as $\mathrm{K}$ and $\mathrm{Ca}$ are macronutrients, i.e., salts, which are needed in more significant amounts for plants' proper development. Furthermore, the increase in the amount of potassium is probably due to the increase in calcium.

Infrared spectroscopy was used to evaluate the molecular structure of samples of fresh-picked and commercial oregano according to treatment temperature. For both sample types, the spectra indicate the presence of aliphatic compounds, by the axial deformation bands of methylene $\left(-\mathrm{CH}_{2}-\right.$ ) and methyl $\left(\mathrm{CH}_{3}^{-}\right)$in the region of 2800-2950 $\mathrm{cm}^{-1}$, and $\mathrm{C}=\mathrm{C}$ ring axial deformations at 1630 $\mathrm{cm}^{-1}$. The presence of a band in the region of $1000-1300 \mathrm{~cm}^{-1}$ indicates CO axial deformation. The band centered in the range of 1680-1750 $\mathrm{cm}^{-1}$ indicates the presence of a carbonyl group $(C=O)$. For both sample types, a broad band was observed between $3200-3500 \mathrm{~cm}$ ${ }^{1}$, characteristic of the axial deformation of $\mathrm{OH}$ intermolecular bonds (Castro, 2004).

For fresh samples (Figure 2), the intensity of characteristic $\mathrm{OH}$ band decreased with rising treatment temperature, allowing us to deduce reduction of free, adsorbed and bound water, as well as volatile compounds commonly present in plants. This is because the heat treatment contributes to the removal of volatile compounds like essential oils, compounds found in large quantities in this species, especially carvacrol and thymol.

By comparing the behavior of the characteristic $\mathrm{OH}$ band of commercial samples with fresh samples, the decrease in intensity of bands for commercial oregano samples is less (Figure 3). This was expected, since the commercial samples had undergone prior dehydrating process before being marketed, therefore eliminating part of their essential oils and other low molecular weight and/or volatile compounds.

The fresh samples showed an increase in band intensity of some bands. This increase might be related to elimination of low molecular weight molecules, which may indicate the presence of other structures. The same behavior can be observed for the commercial samples.

The results of the FTIR technique support the results obtained by the TGA technique.

To better understand the behavior of these types of materials, high-field magnetic resonance imaging (MRI) can be applied a widely-used technique for studying foods that have a high heterogeneity in their composition. It is a nondestructive and non-invasive technique that obtains hydrogen spectra with good spectral resolution in a short time and allows using the sample for further analysis. By this technique, hydrogen spectra were obtained using a $T_{2}$ filter or sequence of CPMG pulses (Car-PurcellMeiboom-Gill). This sequence is intended to eliminate the signals of molecules with short transverse relaxation time $\left(\mathrm{T}_{2}\right)$ and enable better visualization of signals of molecules with low mass. The extended signals, coming mainly of macromolecules, can harm the analysis by causing signal overlap and thereby decrease the amount of information contained in the spectra.

Figure 4 shows the ${ }^{1} \mathrm{H}$ HR-MAS spectrum for the commercial sample dehydrated at $25{ }^{\circ} \mathrm{C}$. 

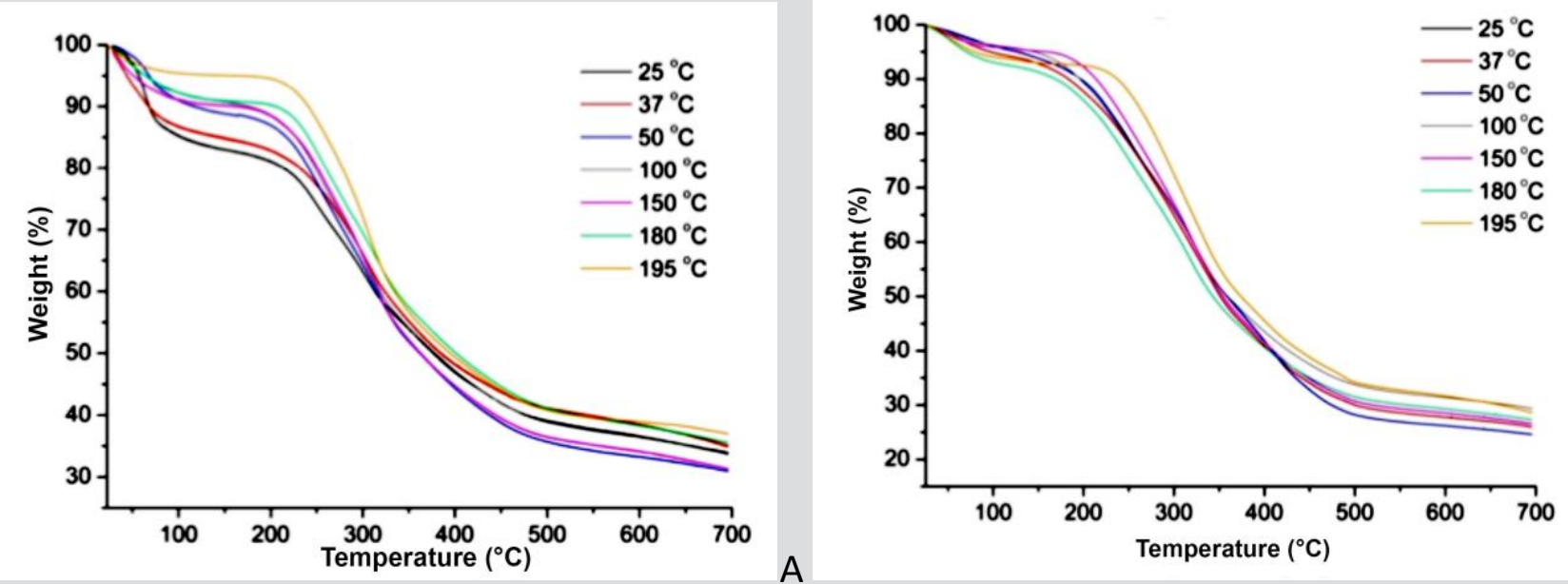

B

Figure 1 - A - TGA curves of the fresh-picked oregano samples, B - TGA curves of the commercial oregano samples
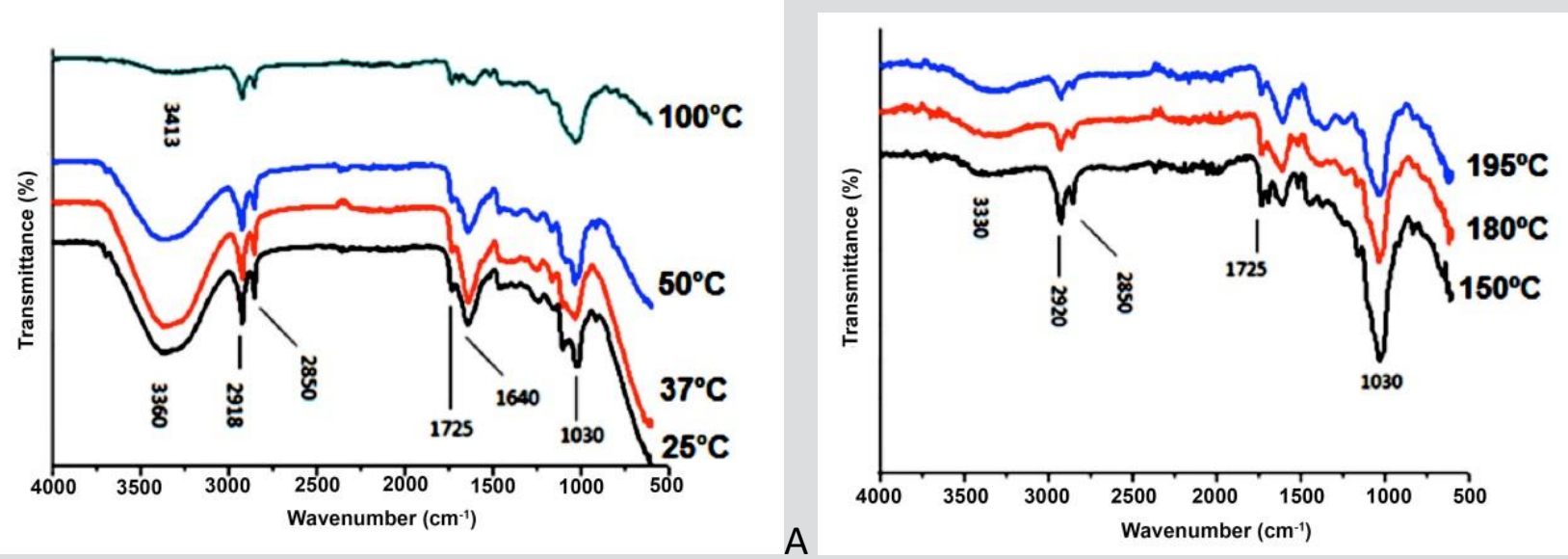

Figure 2 - (A) FTIR spectra of fresh-picked oregano samples dehydrated at $25^{\circ} \mathrm{C}, 37^{\circ} \mathrm{C}, 50^{\circ} \mathrm{C}$ and $100^{\circ} \mathrm{C}(\mathrm{B})$ - FTIR spectra of fresh-picked oregano samples dehydrated at $150{ }^{\circ} \mathrm{C}$ and $180{ }^{\circ} \mathrm{C}$ and $195^{\circ} \mathrm{C}$.
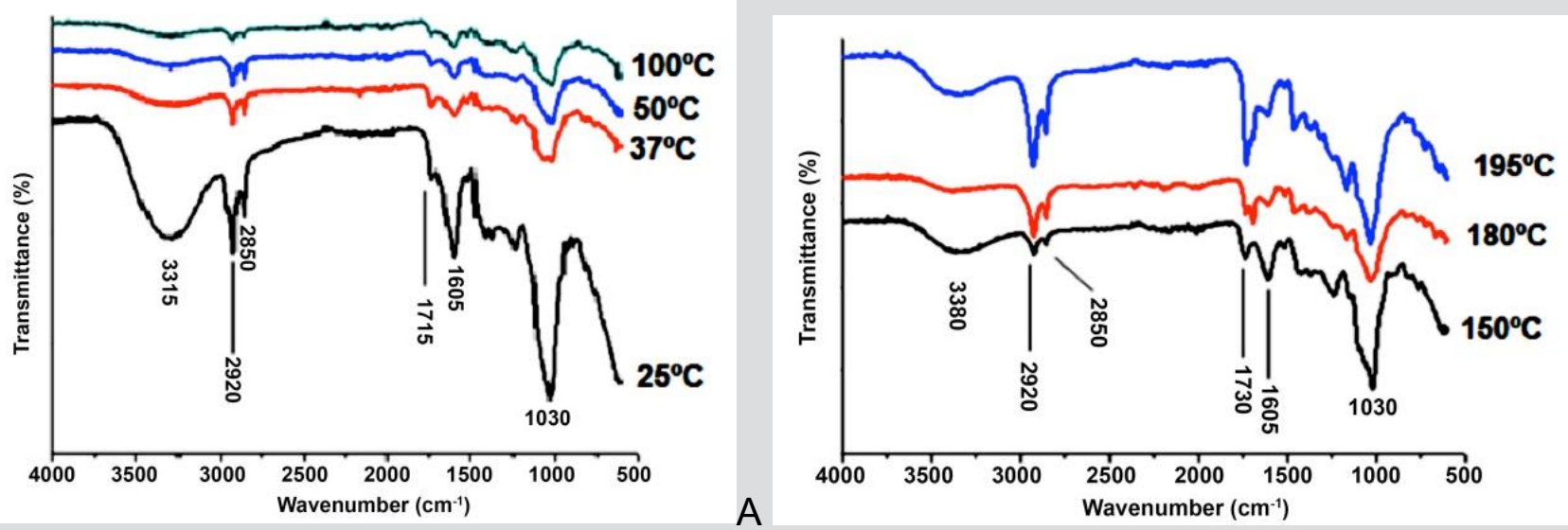

Figure 3 - (A) FTIR spectra of commercial oregano samples dehydrated at $25^{\circ} \mathrm{C}, 37^{\circ} \mathrm{C}, 50^{\circ} \mathrm{C}$ and $100^{\circ} \mathrm{C}$ and (B) FTIR spectra of commercial oregano samples dehydrated at $150^{\circ} \mathrm{C}, 180^{\circ} \mathrm{C}$ and 195 ${ }^{\circ} \mathrm{C}$. 
All samples showed signs in the main spectral regions. The region between 0.8 to $2.5 \mathrm{ppm}$ refers to low molecular weight compounds such as fatty acids, fixed oils of linear chains, for example. The band near 3.0 to 5.5 ppm can be attributed to monosaccharides, disaccharides and polysaccharides, such as cellulose, lignin and others. The bands from $5.5 \mathrm{ppm}$ to 6.5 ppm show the hydrogens related to the $\mathrm{C}=\mathrm{C}$ bonds. The region from 6.5 to $7.5 \mathrm{ppm}$ indicates the presence of aromatic compounds, such as flavonoids, flavones and essential oils.

The hydrogen spectrum showed in the region of 4.5 to $5.5 \mathrm{ppm}$ three different anomeric hydrogens, as confirmed by the presence of characteristic doublets that can be assigned to three different sugar structures. The signal located at 4.75 ppm was attributed to deuterated water. The three doublets with chemical shifts centered at $5.2 \mathrm{ppm} ; 4.9 \mathrm{ppm}$ and $4.6 \mathrm{ppm}$, with J-coupling constants of $3.7 \mathrm{~Hz}, 7.5 \mathrm{~Hz}$ and $7.9 \mathrm{~Hz}$, respectively, present a profile similar to the $\alpha$ and $\beta$ type sugars such as maltose and laminaribiose and other type of sugars, containing its isomers in $\alpha \mathrm{DD}$ and $\alpha \mathrm{DL}$. It was also noted that the structures of these sugars can have their inverted assignment, since they have chemical shift values of their hydrogens very close, requiring additional pulses sequences, such as NMR carbon-13 in solution and/or twodimensional pulse sequences for a precise distinction between the isomeric structures. The basic skeleton of these structures can be found in the literature (Duus, 1994; Ogawa 1991).

The hydrogen nuclei located in the aromatic region show three NMR signals and a pair of doublets at $7.0 \mathrm{ppm}$ with coupling constant as $6,8 \mathrm{ppm} 8.8 \mathrm{~Hz}$ and $9.0 \mathrm{~Hz}$. These data are consistent with the structure of flavonoids. The signal at $6.8 \mathrm{ppm}$ can be attributed to the ring of the basic structure of flavonoids with three substitutions. The region from 3.2 to $4.1 \mathrm{ppm}$ shows other chemical shifts of the hydrogens of the sugar structures, confirming the presence of the sugars mentioned above, according to the data obtained from the literature (Duus et al., 1994; Ogawa et al., 1991).

Regarding the spectral region from 0.5 to $2.5 \mathrm{ppm}$, the signals found are characteristic of compounds with low molecular mass such as esterified fatty acids, essential oils, triacylglycerols and others. Through a comparison with the literature (Mannina et al. 2003; Sacchi et al., 1997; Vigli et al., 2003; Fauhl et al., 2000; Knothe and Kenar, 2004), characteristic signals of most acids fatty were found in most samples. The signal at $\delta 0.8$ can be attributed to the methyl group $\left(-\mathrm{CH}_{3}\right)$, for example, ester linolenate. This signal is a bit more unprotected than other signals of methyl groups due to the proximity of this to a double bond. The signal at $\delta 1.3$ was attributed to all the methylene groups of the fatty acid chains $-\left(\mathrm{CH}_{2}\right)$ $\mathrm{n}$. The signal at $\delta 1.9$ was attributed to methylene a carbonyl groups of fatty acids and esters.

The higher the heat was, the greater the spectral shift was due to elimination of low molecular weight molecules of the chains by degradation, which can be confirmed by the results of TGA and possible structural reorganizations as a function of the spectrum eating. The spectral changes can be observed when comparing the ${ }^{1} \mathrm{H}$ HRMAS of the commercial sample dehydrated at 25 ${ }^{\circ} \mathrm{C}$ with the spectrum of the commercial sample dehydrated at $195^{\circ} \mathrm{C}$ (Figure 5).

Like for the commercial samples, HR-MAS ${ }^{1} \mathrm{H}$ spectra were obtained for the fresh samples. Figure $6 a$ and $6 b$ shows the ${ }^{1} \mathrm{H}$ HR-MAS spectrum of the fresh-picked sample dehydrated at $25^{\circ} \mathrm{C}$ and HRMAS ${ }^{1} \mathrm{H}$ spectrum of the fresh oregano sample dehydrated at $195{ }^{\circ} \mathrm{C}$. The ${ }^{1} \mathrm{H}$ HR-MAS spectrum of this sample already differs compared with the commercial sample spectra. The region from 0.5 to $2.5 \mathrm{ppm}$ is related to the lower molar mass molecules, presenting an increased number of signals. This is because the commercial samples are already subjected to dehydration, to part of their constituents, namely the most volatile ones, are already eliminated. In the fresh-picked samples not subjected to heat treatment (dried at room temperature), the fatty acids, terpenoids, essential oils, water and other low molecular weight compounds were still present.

This can be seen by the spectral change between the fresh samples dried at $25{ }^{\circ} \mathrm{C}$ and $195{ }^{\circ} \mathrm{C}$. This occurs due to the same reasons mentioned regarding the commercial samples, due to elimination of low molecular weight molecules from the chains by degradation and possible structural reorganizations caused by heating, apart from the fact that the fresh samples have higher concentrations of most compounds and 


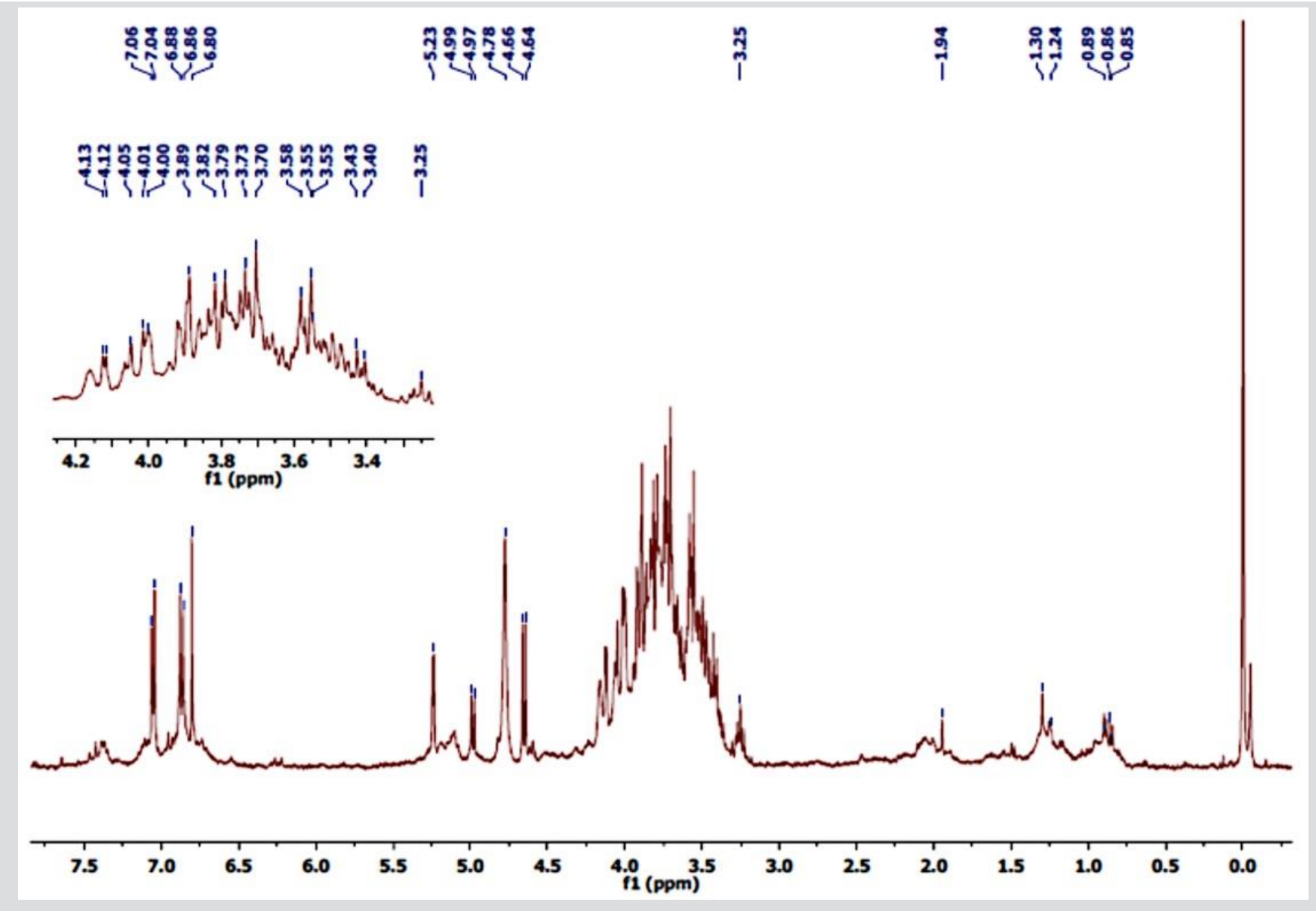

Figure 4 - HRMAS ${ }^{1} \mathrm{H}$ spectrum of commercial oregano sample dehydrated at $25^{\circ} \mathrm{C}$.

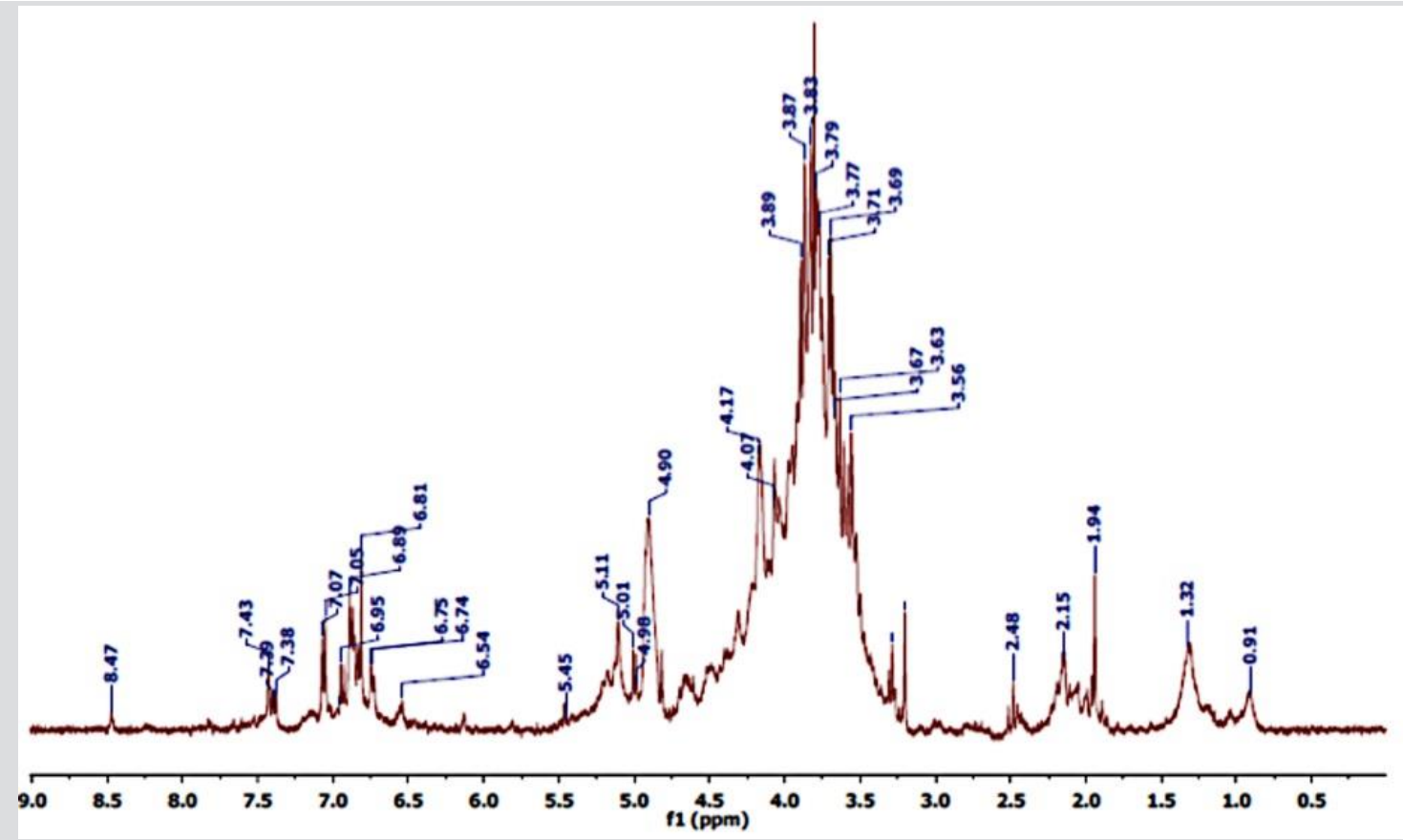

Figure 5 - HRMAS ${ }^{1} \mathrm{H}$ spectrum of the commercial oregano sample dehydrated at $195^{\circ} \mathrm{C}$. 
less stiffness.

The analysis by HR-MAS enabled made it possible to identify and analyze the behavior of the major compounds present in samples, such as water, essential oils and polysaccharides such as cellulose and lignin, as was already done by other researches (Costa et al., 2007; Preto et al., 2013).

\section{4 - CONCLUSION}

In this study, we applied TGA, EDX, FTIR, solid-state high-field NMR through HR-MAS to characterize commercial and fresh-picked samples of Origanum vulgare, to detect the changes in the type of compounds present in the samples when subjected to heat treatment. In particular, we applied solid-state high-field NMR, through the HR-MAS technique, to detect the compounds found in greater amounts in the samples. The results obtained by this technique were compared with complementary FTIR and TGA investigation. The high-field NMR revealed that the samples had essentially the same composition, with a variation in quantity because the commercial samples had already been subjected to preliminary dehydration to increase shelf life. The differences detected between samples observed by TGA and FTIR were confirmed by high-field NMR spectroscopy. The possibility of using the NMR technique to differentiate between samples from different sources is very promising, with the advantage that this technique can be used with intact samples.

We also conclude that the commercial sample has more long time of shelf due to the pre dehydration process than the fresh sample. However, for the best use of the beneficial substances of Origanum vulgare the ideal would be to use it fresh at ambient temperature. For cooking, both have a more or less the same behavior, but it is not very good to cook Origanum vulgare at higher temperatures. So, the best is to consume the herbs as it is, in nature.

\section{Acknowledgements}

We thank the Brazilian agencies CAPES, CNPQ and FAPERJ for the grants.
Baratta, M.T. et al. (1998) Chemical composition, antimicrobial and antioxidative activity of laurel, sage, rosemary oregano and coriander essential oils. Journal of Essential Oil Research, 10, 618-627.

Chen, H. X.; zhang, M.; chen, H. (2005). Components and antioxidant activity of polysaccharide conjugate from green tea. Food Chemistry, 90, 17-21.

Claridge, T. D. W. (1999). High-Resolution NMR Techniques in Organic Chemistry. (2th ed.) Amsterdam.

Cornillon, P.; Salim, L. C. (2000) Characterization of water mobility and distribution in low-and intermediate- moisture food systems. Magnetic Resonance Imaging, 18, 335-341

Costa P. M., Tavares M. I. B, Silva E. O, Bathista A.L.B.S., Nogueira J. S., Filho N. P, Ferreira A. G., Barison A., Daolio C., Vizzotto L. (2007) The use of ${ }^{1} \mathrm{H}$ - HRMAS to evaluate the Gelatinisation process of Starches derived from tropical fruit seed. International Journal of Polymeric Materials, 56, 1135-1143

Duus, J. ,Bock, K., Ogawa, S. (1994). An NMR spectroscopic and conformational study of 12 pseudo-disaccharides (d-glucopyranosyl-5a-carba-d-and-I-glucopyranoses). Carbohydrate Research, 252, 1-18.

Fauhl, C.; Reniero, F.; Guillou, C. (2000). ${ }^{1} \mathrm{H}$ NMR as a tool for the analysis of mixtures of virgin olive oil with oils of different botanical origin. Magnetic Resonance in Chemistry. 38, 436-443.

Gligorov, J.; Lotz, J. (2004). Preclinical pharmacology of the taxanes: implications of the differences. The Oncologist, 9, 3-8.

Harris R. K., Recent advances in solid state NMR. The Fifth International Conference on Applications of Magnetic Resonance in Food Science 2000; I: 1-11. Aveiro, Portugal

Hijo, A. A. C.T.; da Costa, J. M.G.; Silva, E. K.; Azevedo, V. M.; Yoshida, M.I.; Borges, S. V. (2014). Physical and thermal properties of oregano (Origanum vulgare I.) Essential oil microparticles. Journal of Food Process Engineering, 38, 1-10.

Hills, B. P.; BELTON, P.; WEBB, G. (1999), Advances in Magnetic Resonance in Food Science. Special Publications. UK: RSC Publishing, 289p.

Knothe, G.; Kenar, J. A. (2004) Determination of the fatty acid profile by ${ }^{1} \mathrm{H}-\mathrm{NMR}$ spectroscopy. European Journal of Lipid Science and Technology. 106, 88-96.

Lião, L. M. et al. Perfil químico de cultivares de feijão (phaseolus vulgaris) pela técnica de high resolution

\section{REFERENCES}




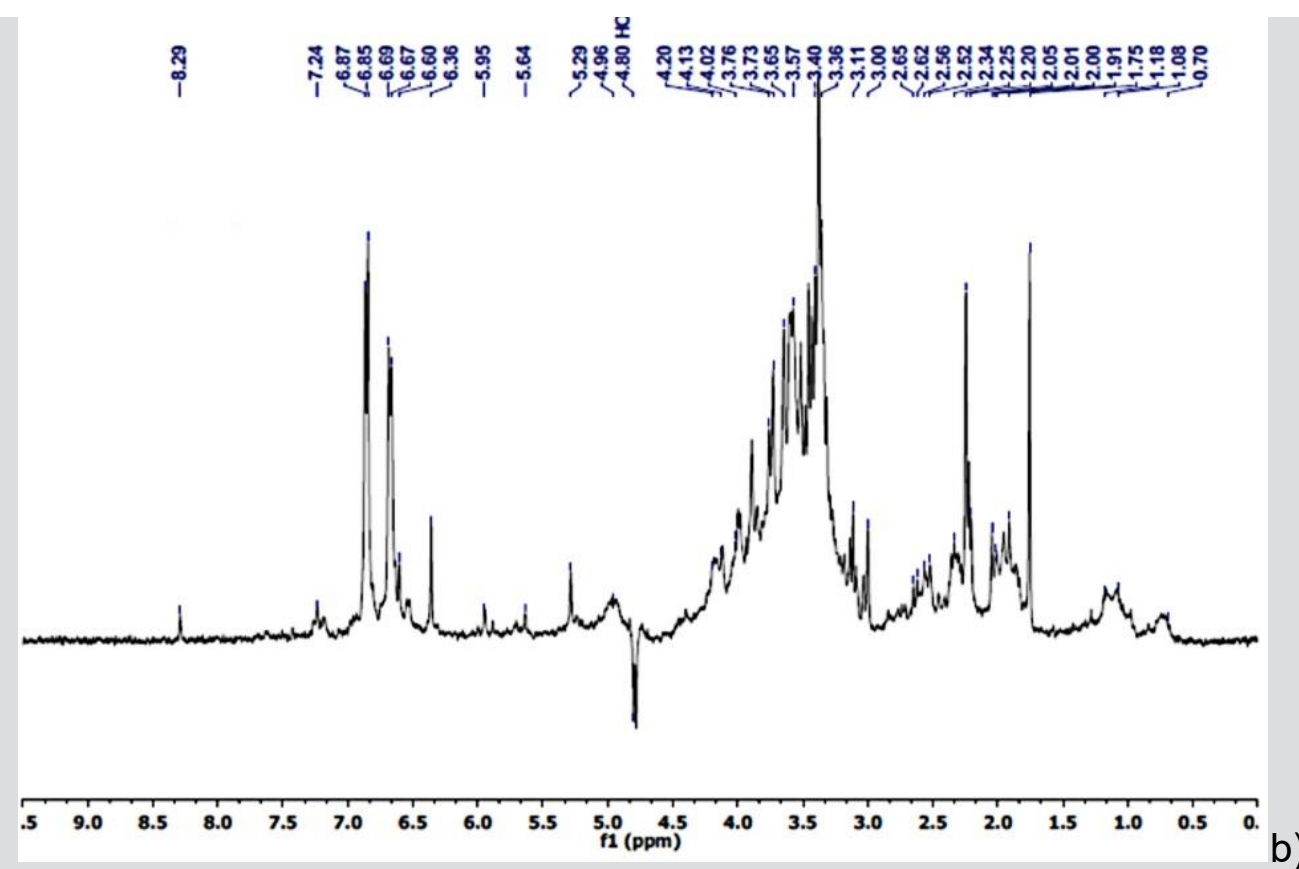

Figure 6: a) HR-MAS $1 \mathrm{H}$ spectrum of the fresh oregano sample dehydrated at $25^{\circ} \mathrm{C}$, b) HRMAS $1 \mathrm{H}$ spectrum of the fresh oregano sample dehydrated at $195^{\circ} \mathrm{C}$

Magic angle spinning (HRMAS). Química Nova, v. 33, n. 3, 634-638, 2010.

MALAVOLTA, E. Manual de nutrição mineral de plantas. São Paulo: Agronômica Ceres, 2006. 638p

Mannina, L.; Viel, S.; Capitani, D.; Segre, S. (2003). Diffusion-Ordered NMR Spectroscopy: A Versatile Tool for the Molecular Weight Determination of Uncharged Polysaccharides. Biomacromolecules, 4, 1843-1847.

Ogawa, S. Sugawa, I. Shibata, Y. (1994). Synthesis of pseudo-laminarobiose,-cellobiose, and-maltose (D-glucopyranosyl 5a-carba-D-and L-glucopyranoses). Carbohydrate Research, 252, 1-18.

Preto, M. S. M.; Tavares, M.I.B.; Sebastiao, P. J. O. (2011) Caracterização dos Constituintes Poliméricos da Maytenus ilicifolia por Relaxação Nuclear de ${ }^{1} \mathrm{H}$ por RMN no Estado Sólido. Polímeros, 21, 416420.

Preto M. S. de M., Tavares M. I. B, Sebastião P. J. O., Azeredo, R. B. V, (2013) Determination of herb authenticity by Low-Field NMR Food Chemistry, A, $116,4890-4901$

Sacchi, R.; Addeo, F.; Paolillo, L. (1997). ${ }^{1} \mathrm{H}$ and ${ }^{13} \mathrm{C}$ NMR of virgin olive oil: An overview. Magnetic Resonance in Chemistry, 35, S133-S145.

Sacco, A. et al. (1998) Preliminary Investigation on the Characterization of Durum Wheat Flours Coming from Some Areas of South Italy by Means of ${ }^{1} \mathrm{H}$ High-Resolution Magic Angle Spinning Nuclear Magnetic Resonance. Journal of Agricultural and
Food Chemistry, 46, 4242-4249.

Salomonsen, Ti., et al. (2007) Water mobility in acidified milk drinks studied by low-field ${ }^{1} \mathrm{H}$ NMR. International Dairy Journal, 17, 294-301.

Sivropoulou, A. et al. (1996) Antimicrobial and Cytotoxic Actives of Origanum Essential Oils. Journal of Agricultural and Food Chemistry, Thessaloniki, 44, 1202-1205.

Souza, E. L. et al. (2005) Orégano (Origanum vulgare L. lamiaceae): uma especiaria como potencial fonte de compostos antibicrobianos. Revista Higiene Alimentar, 19, 40-45.

Tavares, M.I.B. et al. (2003) Molecular dynamic study of the starch obtained from the Mangifera indica Cv. Bourbon and Espada seeds by ${ }^{13} \mathrm{C}$ solid state NMR. Carbohydrate Polymers, 53, 213-216.

Teixeira, B., Marques, A., Ramos, C., Serrano, C., Matos, O., Neng, N. R., Nogueira, J. M. F., Saraiva, J. A. and Nunes, M. L. (2013), Chemical composition and bioactivity of different oregano (Origanum vulgare) extracts and essential oil. Journal of the Science of Food and Agriculture, 93: 2707-2714

Vigli, G.; Philippidis, A.; Spyros, A.; Dais, P. (2003). Classification of edible oils by employing ${ }^{31} \mathrm{P}$ and ${ }^{1} \mathrm{H}$ NMR spectroscopy in combination with multivariate statistical analysis. A proposal for the detection of seed oils adulteration in virgin olive oils. Journal of Agricultural and Food Chemistry, 51, 5715-5722. 